vasculitis. ${ }^{5}$ Papillitis, haemorrhages and sheathing of vessels was observed in these patients. ${ }^{5-7}$

The treatments employed in these previous reports have been prednisone or cyclophosphamide plus corticosteroids. The improve-

1 Hopkins DJ, Horan E, Burton IL, Clamp SE, De Domball FT, Goligher JC. Ocular disorders in a series of 332 patients with Crohn's disease. Br $\mathcal{f}$ Ophthalmol 1974; 58: 732-7.

2 Greenstein AJ, Janowitz HD, Sachar DB. The extraintestinal complications of Crohn's disease and ulcerative colitis: a study of 700 patients. Medicine 1976; 55: 401-11.

3 Petrelli EA, McKinley M, Troncale FJ. Ocular manifestations of inflammatory bowel disease. Ann Ophthalmol 1982; 14: $356-60$

4 Schneiderman JH, Sharpe JA, Sutton DMC. Cerebral and retinal vascular complications of inflammatory bowel disease. Ann Neurol 1979; 5: 331-7.

5 Duker JS, Brown GC, Brooks I. Retinal vasculitis in

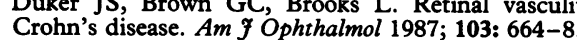

6 Sedwick LA, Klingele TC, Burde RM, Behrens MM. Optic neuritis in inflammatory bowel disease. $\mathcal{F}$ Clin Neuro Oph-

Macoul KI. Ocular changes in granulomatus ileocolitis. Arch Ophthalmol 1970; 84: 95-7.

8 Novotny DA, Rubin RJ, Slezak FA, Porter JA. Arterial thromboembolic complications of inflammatory bowel disease. Dis Colon Rectum 1992; 35: 193-6. ment of the ocular damage was limited..$^{5-7}$ In our case, we used cyclophosphamide plus prednisone, but only the uveitis and vitritis improved. The retinal vessel lesions did not improve.

9 Wackers FJ, Tytgat GN, Vreeken J. Necrotizing vasculiti and ulcerative colitis. $B M \mathcal{F}$ 1974; 4: 83-4.

10 Nelson JN, Barron MM, Riggs JE, Gutmann L, Schochet SS. Cerebral vasculitis and ulcerative colitis. Neurology 1986; 36: 719-21.

11 Wakefield AJ, Dhillon AP, Rowles PM, et al. Pathogenesis of Crohn's disease: multifocal gastrointestinal infarction. Lancet 1989; 2: 1057-62.

12 Collins WJ, Bendig DW, Taylor WF. Pulmonary vasculiti complicating childhood ulcerative colitis. Gastroenterology 1979; 77: 1091-3.

13 Wakefield AJ, Sankey EA, Dhillon AP, et al. Granulomatous vasculitis in Crohn's disease. Gastroenterology 1991; 100 $1279-87$

14 Jampol LM, Isenberg SJ, Goldberg MF. Occlusive retina arteriolitis with neovascularization. Am $\mathcal{F}$ Ophthalmol 1976 81: 583-9.

\title{
Occult small bowel adenocarcinoma complicating Crohn's disease: a report of three cases
}

\author{
CD Gillen, CA Wilson, RS Walmsley, DSA Sanders, ST O'Dwyer, RN Allan
}

\begin{abstract}
Summary
Three patients with Crohn's disease are described who were treated by ileal resection for intestinal obstruction. Histological examination of the resected specimen in each case established the diagnosis of adenocarcinoma of the small intestine complicating Crohn's disease. This diagnosis should be considered in patients with longstanding macroscopic Crohn's disease who present with severe or recurrent symptoms. The diagnosis may not be apparent on routine radiological examination or even macroscopically at laparotomy.
\end{abstract}

Keywords: Crohn's disease, small bowel, adenocarcinoma

Queen Elizabeth

Hospital, Edgbaston, Birmingham, UK

CD Gillen

RS Walmsley

ST O'Dwyer

RN Allan

Department of

Histopathology

CA Wilson

DSA Sanders

Correspondence to

Dr CD Gillen,

Queen Elizabeth Hospital,

Edgbaston, Birmingham

B15 2TH, UK

Accepted 4 October 1994 the management of patients with longstanding macroscopic small bowel Crohn's disease. ${ }^{4}$ In this paper we describe three examples of adenocarcinoma of the ileum complicating Crohn's disease which were only apparent on histological examination of the resected specimens.

\section{Case reports}

\section{Case 1}

A diagnosis of ileal Crohn's disease in this white man, born in June 1949, was established on radiological examination in 1969 . He had further abdominal symptoms in 1975 when radiological studies confirmed the changes of terminal ileal Crohn's disease with a localised ileocaecal fistula. He re-presented in July 1992 with a three month history of right-sided colicky abdominal pain, nausea, intermittent constipation and $10 \mathrm{~kg}$ weight loss. Further radiological assessment confirmed an irregular $8 \mathrm{~cm}$ of terminal ileum with abnormal mucosa and several areas of narrowing with mucosal irregularity adjacent to the ileo-caecal valve. At laparotomy the appearance macroscopically was described as typical of Crohn's disease and he was treated by distal ileal resection. The resected specimen comprised an $11 \mathrm{~cm}$ length of small bowel with a $4 \mathrm{~cm}$ diameter ulcerated area with some transmural thickening. There were three distinct areas of mucosal irregularity. Macroscopically, the changes were considered typical of Crohn's disease. However histological examination revealed a moderately well differentiated adenocarcinoma, extending 
through the bowel wall and invading muscle (figure 1). One group of dysplastic glands was identified in the small bowel mucosa adjacent to the tumour and there was evidence of perineural tumour spread and foci of submucosal lymphatic invasion. The lymph nodes examined from the first operative specimen were clear. The irregular mucosa contained foci of submucosal scarring consistent with quiescent Crohn's disease but there was no evidence of active disease.

In view of the histological evidence of adenocarcinoma of the ileum a further laparotomy was undertaken when a right hemicolectomy was performed. Histological examination of the resected specimen showed that two of the 11 lymph nodes examined were replaced by carcinoma.

The patient made an excellent post-operative recovery and received adjuvant therapy with 5-fluorouracil and levamisole. Unfortunately, the patient now (February 1994) has hepatic and pelvic metastases.

Case 2

The patient was a white woman, born October 1915, with a 30-year history of mild intermittent bouts of vomiting, diarrhoea and abdominal distention which had been attributed to the irritable bowel syndrome. She developed further symptoms in 1988 when a barium enema examination was reported as normal (?filling of distal ileum). She re-presented in October 1992 with a four year history of similar symptoms. Physical examination revealed a tender right iliac fossa mass. A barium follow-through examination showed several strictures in the

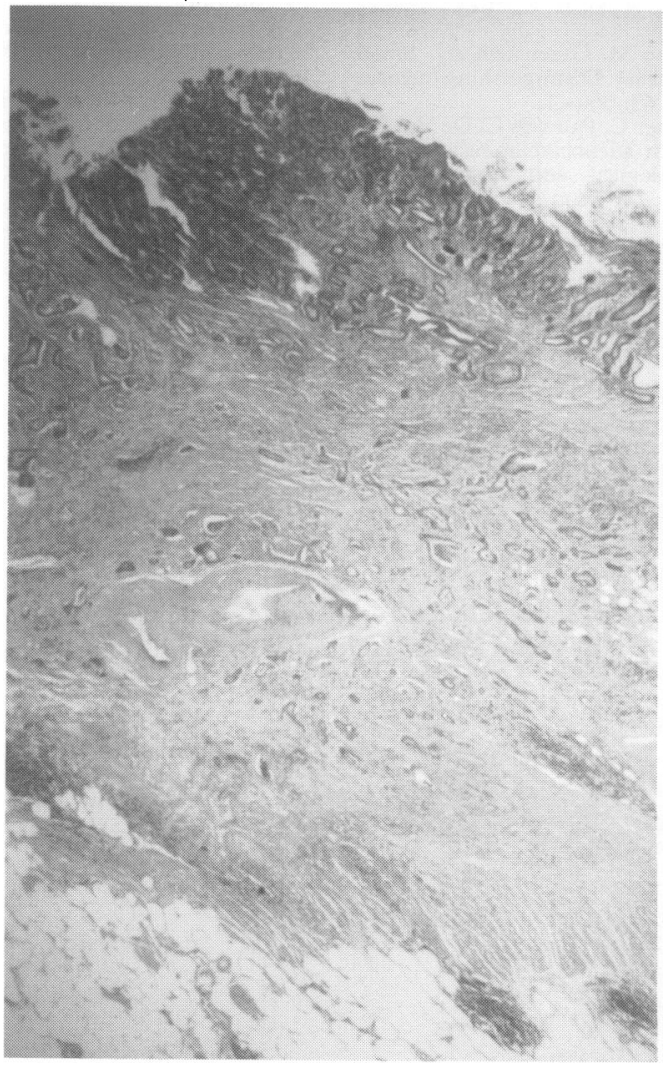

Figure 1 Adenocarcinoma of the ileum invading muscle (H\&E) distal ileum and an inflammatory mass consistent with Crohn's disease. At laparotomy there were matted loops of small bowel in the right iliac fossa with an ileocaecal fistula and an ileal stricture $15 \mathrm{~cm}$ proximal to the matted loops. Histological examination revealed a Duke's B adenocarcinoma of the distal ileum. There were no metastases in the resected lymph nodes. The patient made an uncomplicated recovery. In view of her age, re-operation was not undertaken and she remains well (February 1994).

\section{Case 3}

The patient was a white man, born in September 1946, in whom Crohn's disease of the distal ileum and right colon was diagnosed in 1967 and treated conservatively. He was admitted acutely in October 1992, aged 46 years, with a one month history of abdominal pain, diarrhoea, and vomiting. Barium enema examination showed changes consistent with a carcinoma at the hepatic flexure and multiple strictures in the distal ileum consistent with Crohn's disease. A laparotomy revealed extensive Crohn's colitis with a mobile colonic carcinoma just distal to the hepatic flexure with changes of Crohn's disease in the distal ileum. There were no hepatic or peritoneal metastases. The distal ileum and right colon were resected and continuity restored with an ileocolonic anastomosis. Histological examination of the resected specimen confirmed Crohn's colitis, complicated by Duke's B adenocarcinoma of the colon. In addition there was an ileal adenocarcinoma and histological evidence of Crohn's disease (figure 2). There was no vascular invasion or lymph node involvement.

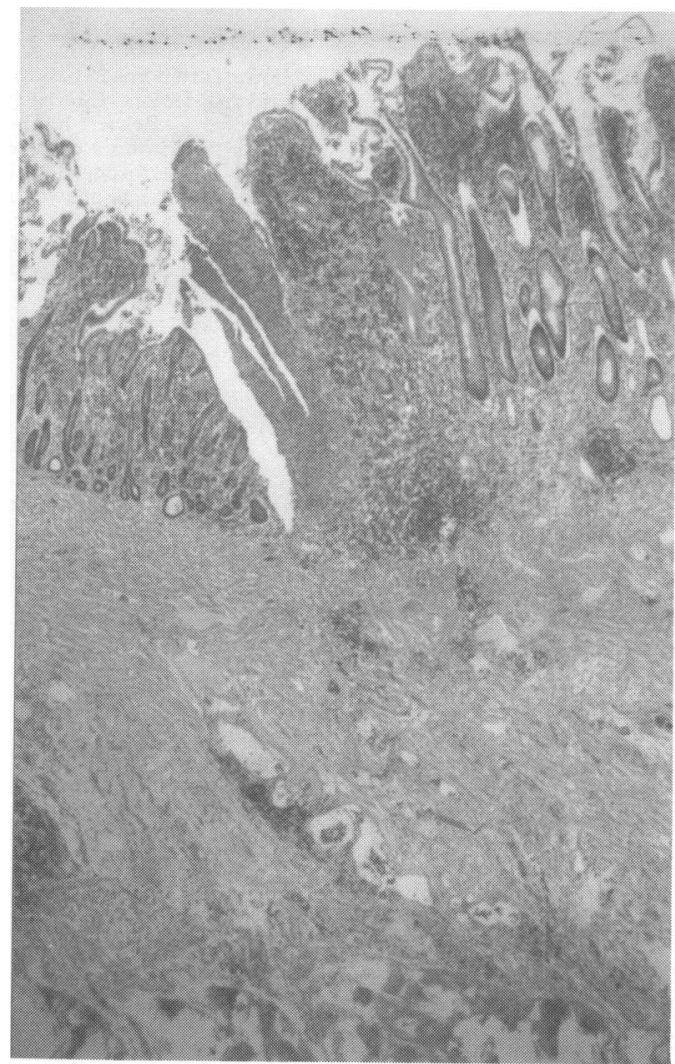

Figure 2 Ileal Crohn's disease with fissuring ulceration (H\&E) 
Despite post-operative complications which included pulmonary embolus, subclavian venous thrombosis and an enterocutaneous fistula, he improved with conservative managment and was fit and well when last reviewed in February 1994.

\section{Discussion}

Since Ginzburg et $a l^{15}$ published the first report of adenocarcinoma of the ileum complicating Crohn's disease, 61 examples had been published in 1982 and there have been 60 examples since, a total of 121 . The largest reported series described 20 small bowel cancers in 19 patients with Crohn's disease between 1960 and $1989 .{ }^{16}$ Since bypass surgery is no longer in vogue and diseased ileal segments are often resected, fewer may be seen in future. No examples of small bowel adenocarcinoma complicating Crohn's disease were identified in a recent view of 1008 Crohn's patients in the Aberdeen area. ${ }^{17}$

These three examples of occult adenocarcinoma complicating Crohn's disease emphasise that routine radiological assessment

1 Ekbom A, Helmick C, Zack M, Hans-Olov A. Increased risk of large bowel cancer in Crohn's disease with colonic involvement. Lancet 1990; 336: 357-9.

2 Gillen CD, Andrews HA, Prior P, Allan RN. Crohn's disease and colorectal cancer. Gut 1994; 35: 651-5.

3 Gillen CD, Andrews HA, Prior P, Allan RN. Ulcerative colitis \& Crohn's disease: a comparison of the colorectal cancer risk in extensive colitis. Gut 1994; in press.

4 Hawker PC, Gyde SN, Thompson H, Allan RN. Adenocarcinoma of the small intestine complicating Crohn's disease. Gut 1982; 23: 188-93.

5 Fresko D, Lazarus SS, Dotan J, Reingold M. Early presentation of carcinoma of the small bowel in Crohn's disease ('Crohn's carcinoma'). Gastroenterology 1982; 82: 783-9.

6 Collier PE, Turowski P, Diamond DL. Small intestina adenocarcinoma complicating regional enteritis. Cancer 1985; 55: 516-21.

7 Senay E, Sachar DB, Keohane M, Greenstein AJ. Small bowel carcinoma in Crohn's disease. Distinguishing features and risk factors. Cancer 1989; 63: 360-3.

8 Cuvelier C, Bekaert E, De Potter C, Pauwels C, De Vos M Roels H. Crohn's disease with adenocarcinoma and dysplasia. Macroscopical, histological and immunohistochemical aspects of two cases. Am $\mathcal{F}$ Surg Pathol 1989; 13 187-96.

9 Richards ME, Rickert RR, Nance FC. Crohn's diseaseassociated carcinoma. A poorly recognised complication of inflammatory bowel disease. Ann Surg 1989; 209: 764-73.

\section{Summary}

- consider bowel carcinoma in a Crohn's patient with recurrent symptoms after a long asymptomatic interval

- the adenocarcinoma may not be apparent on radiological examination

and macroscopic evaluation at laparotomy may overlook this complication since in all three examples, the adenocarcinoma of the small intestine was only identified on histological examination. It is of interest that one case presented with synchronous adenocarcinoma of the ileum and colon.

To ensure optimal management of patients with longstanding macroscopic Crohn's disease of the small intestine who present with recurrent symptoms after a long asymptomatic interval, the possibility of malignancy should be considered and resection advised, since exclusion of adenocarcinoma of the small bowe on radiological or macroscopic grounds alone remains extremely difficult.

10 Sherlock DJ, Suarez V, Gray JG. Stomal adenocarcinoma in Crohn's disease. Gut 1990; 31: 1329-32.

11 Bastug DF, Cochran RC, Caldwell R, Foster D. Adenocarcinoma of the small intestine in Crohn's disease: a unique finding. $W V$ Med 7 1991; 87: 295-8.

12 Ribeiro MB, Greenstein AJ, Heimann TM, Yamazaki Y, Aufses AH. Adenocarcinoma of the small intestine Crohn's disease. Surg Gynaecol Obstet 1991; 38: 343-9.

13 Crotta S, Cerrato C, Sansonna F, Allieta R, Parini U, Chasseur D. Adenocarcinoma ileale nel morbo di Crohn. Descrizione di 2 casi. Minerva Dietol Gastroenterol 1992; 38: 211-6.

14 Eitan B, Zisman I, Qarawany M, Grishkan A, Mazor A Crohn's disease of small bowel manifested by obstructive carcinoma. Harefuah 1993; 125; 209-11.

15 Ginzburg L, Schneider KM, Dreizin DH, Levinson C. Carcinoma of the jejunum occurring in a case of regional Carcinoma of the jejunum occurrin

16 Ribeiro MB, Greenstein AJ, Heimann TM, Yamazaki Y, Aufses AH. Adenocarcinoma of the small intestine in Aufses AH. Adenocarcinoma of the small intestine

17 Kyle J, Ewen SWB. Two types of colorectal carcinoma in Crohn's disease. Ann R Coll Surg Engl 1992; 74: 387-90. 